\title{
Fuzzy Assessment of Steel Deck Pavement for Long Suspension Bridge of the Fourth Nanjing Yangtze River Bridge
}

\author{
Jinyu Zong, ${ }^{1,2}$ Keqiang Zhang, ${ }^{1,2}$ Binggen Zhan, ${ }^{3}$ and Rui Ma $\mathbb{D}^{4,5}$ \\ ${ }^{1}$ JSTI Group, Nanjing 211112, China \\ ${ }^{2}$ National Engineering Laboratory of New Road Materials, Nanjing 211112, China \\ ${ }^{3}$ College of Civil Engineering, Hefei University of Technology, Hefei 230009, China \\ ${ }^{4}$ Anhui Province Engineering Laboratory of Advanced Building Materials, Anhui Jianzhu University, Hefei 230601, China \\ ${ }^{5}$ Anhui Province Key Laboratory of Advanced Building Materials, Anhui Jianzhu University, Hefei 230601, China \\ Correspondence should be addressed to Rui Ma; marui1251@163.com
}

Received 11 March 2020; Revised 9 November 2020; Accepted 25 January 2021; Published 8 February 2021

Academic Editor: Xue Luo

Copyright (c) 2021 Jinyu Zong et al. This is an open access article distributed under the Creative Commons Attribution License, which permits unrestricted use, distribution, and reproduction in any medium, provided the original work is properly cited.

\begin{abstract}
The Fourth Nanjing Yangtze River Bridge (the Fourth Bridge) with the main span of $1418 \mathrm{~m}$ is the largest three-span suspension bridge in China and the third largest in the world. The service circumstance of steel deck pavement on the Fourth Bridge is complex and severe, so that the scheme evaluation for steel deck pavement is a huge program. To rapidly and comprehensively evaluate the schemes for pavement, a fuzzy evaluation method was introduced in this paper. A three-level logical assessment structure including 21 basic impact factors was built according to analytic hierarchy process (AHP), and the weight for each judgment matrix was determined by the Delphi method. Consequently, a fuzzy evaluation theory was used to value each scheme to propose the optimal one. Based on this method, four pavement schemes were evaluated to choose the optimal one, and the performance of the optimal scheme was highly corresponding to the practical engineering practice. The fuzzy evaluation method can supply a theoretical support to fast determine the scheme for long-span steel deck pavement.
\end{abstract}

\section{Introduction}

Steel deck pavement is a single- or multilayer composite which paved on the steel bridge decks for protection and satisfaction of the requirement of traffic. With the growing numbers of super engineering projects in decades [1-6], steel deck pavement became more and more important in bridge construction and drew much more attentions in research [7-15]. With the continuous developing and improving, several pavement techniques, such as gussasphalt method [16-19], mastic asphalt method [20-22], epoxy asphalt (EA) method [23-25], and stone mastic asphalt (SMA) method [26-29], performed good properties and were popularized in field application. In China, the improved techniques, for instance, epoxy-resin-stone multilayer pavement and double-layer SMA pavement [30-32], were also well developed to satisfy the local requirement and exhibit good performance. However, cracks and pits are still the main diseases that threaten the service life of asphalt pavement. Although some works were carried out to investigate the propagation or healing properties of cracks [33]. For instance, Li [34] studied the healing properties of asphalt binders at different damage levels by comparative analysing of crack length $(\mathrm{CL})$, pseudoshear stiffness (S), and dissipated pseudostrain energy (DPSE). The results show that the CL-based healing index was a fundamental and accurate parameter to evaluate the healing rate and healing potential of the bitumen. The life prediction for pavement is also important during the bridge construction.

The durability of steel bridge deck pavement was significantly influenced by its material intrinsic properties, cast and curing regime, and geographical, climatic, and traffic conditions so that the pavement performance of each individual bridge was far different. Plenty of research studies were carried out to well evaluate the failure model of steel deck pavement $[17,29,30,35-41]$. Luo et al. [42] 
investigated the fatigue life of epoxy asphalt concrete (EAC) through four criteria, the yield point, the half modulus ratio (SR) point, the peak phase angle point, and the sample failure. The results proved that the fatigue life of EAC was higher than conventional asphalt concrete by one or two orders in magnitude, and EAC pavement was suggested for steel box girder bridges. However, the influence factors for steel deck pavement were various and intricate. Most works focused on only one or two aspects, and the investigation that considered all influence factors and implied an integrated evaluation was rarely reported. Analytic hierarchy process (AHP) is a method for multiobject decision. By the AHP method, the ultimate object is divided into small component elements; then, a hierarchical structure is built for elements based on logical relationship, and the relative importance between elements is determined after comparison. Although the AHP method is developed many years $[43,44]$, its application on steel deck pavement is still limited.

The Fourth Yangtze River Bridge (the Fourth Bridge) is an important component in the national highway network. The bridge is a three-span suspension bridge, with the length of $5.448 \mathrm{~km}$ across the river and the main span of $1.418 \mathrm{~km}$, which is the largest in China and the third largest in the world. The bridge was designed for six-lane highway in two directions, allowed the maximum speed of $100 \mathrm{~km} / \mathrm{h}$. Moreover, the environment and the traffic load were also severe. The Fourth Bridge is located at Nanjing, the daily temperature can reach $43^{\circ} \mathrm{C}$ in maximum and $-14^{\circ} \mathrm{C}$ in minimum, and the temperature inside the pavement layer can even achieve $70^{\circ} \mathrm{C}$ during summer. Still, the overload ratio of the traffic may exceed $25 \%$. The stability and the durability of the pavement under the heavy temperature and load condition are significantly important.

In this paper, a fast and comprehensive assessment method was established to determine the steel deck pavement scheme for the Fourth Bridge. The influence factors for pavement stability and durability were analysed by the AHP method to build a progressive hierarchical structure, and then the comparison between each two criteria was conducted using the Delphi method. After that, four pavement schemes were compared with a score circulated by fuzzy theory to assess an optimal one. This method supplied a fast resolution for the scheme evaluation of steel deck pavement.

\section{Methodology}

2.1. Establishing the Hierarchical Structure. Referred to the research papers and practices about steel deck pavement and considered the pavement properties and the functional relationship among factors, a three-level structure was built according to the AHP method [45], as shown in Figure 1. The object layer was the purpose of pavement and used for scheme assessment. The rule level contained the judgment rules for applications, including pavement performance, construction stability, maintenance, and economic benefit. The criterion level was built for detailed properties of pavement and contained 21 factors.
2.2. Establishing the Judge Matrix. According to the AHP method, a pair-wise comparison between each two elements was used instead of a comprehensive comparison. The relative importance of element $i$ to element $j$ was denoted as $a_{i j}$. Then, a judgment matrix $U$ was built as

$$
U=\left[\begin{array}{cccc}
1 & a_{12} & \ldots & a_{1 n} \\
a_{21} & \ldots & a_{i j} & \ldots \\
\ldots & a_{j i}=\frac{1}{a_{i j}} & \ldots & \ldots \\
a_{n 1} & \ldots & \ldots & 1
\end{array}\right] .
$$

The value of $a_{i j}$ in $U$ was quantified from 1 to 9 according to the relative importance by the Delphi method [46, 47], as shown in Table 1 [45]. After that, based on the judgment matrix, the weight distribution vector $W$ was calculated with the following equation:

$$
\begin{aligned}
M_{i} & =\prod_{j=1}^{n} a_{i j}, \quad i=1,2, \ldots, n, \\
\overline{W_{i}} & =\sqrt[n]{M_{i}}, \\
w_{i} & =\frac{\overline{W_{1}}}{\sum_{i=1}^{n} \overline{W_{i}}}, \\
W & =\left[w_{1}, w_{2}, \ldots, w_{n}\right],
\end{aligned}
$$

where $M_{i}$ is the product for elements in row $i, \overline{W_{i}}$ is the $n$ times roots of $M_{i}$, and $w_{i}$ is the normalization for $\overline{W_{i}}$.

2.3. The Consistency Check for Judgment Matrix. Since the value of elements in the judgment matrix was determined by the Delphi method, which was subjectively, the consistency check for weight distribution vector $W$ was necessary. The check process was proceeded by the following:

$$
\begin{aligned}
\mathrm{CI} & =\frac{\left(\lambda_{\max }-n\right)}{(n-1)}, \\
\mathrm{CR} & =\frac{\mathrm{CI}}{\mathrm{RI}},
\end{aligned}
$$

where $\mathrm{CI}$ is the consistency index, $n$ is the dimension of the matrix, RI is the random consistency index, and CR is the consistency ratio. $\lambda_{\max }$ is the maximum characteristic root for matrix $U$ and can be calculated from

$$
U \cdot W=\lambda_{\max } \cdot W .
$$

$\mathrm{RI}$ is the average CI from 500 randomly filled matrixes, and the calculated results by Saaty are listed in Table 2 [48]. If $\mathrm{CR}$ is less than $10 \%$, the matrix can be considered as having an acceptable consistency [48]. 


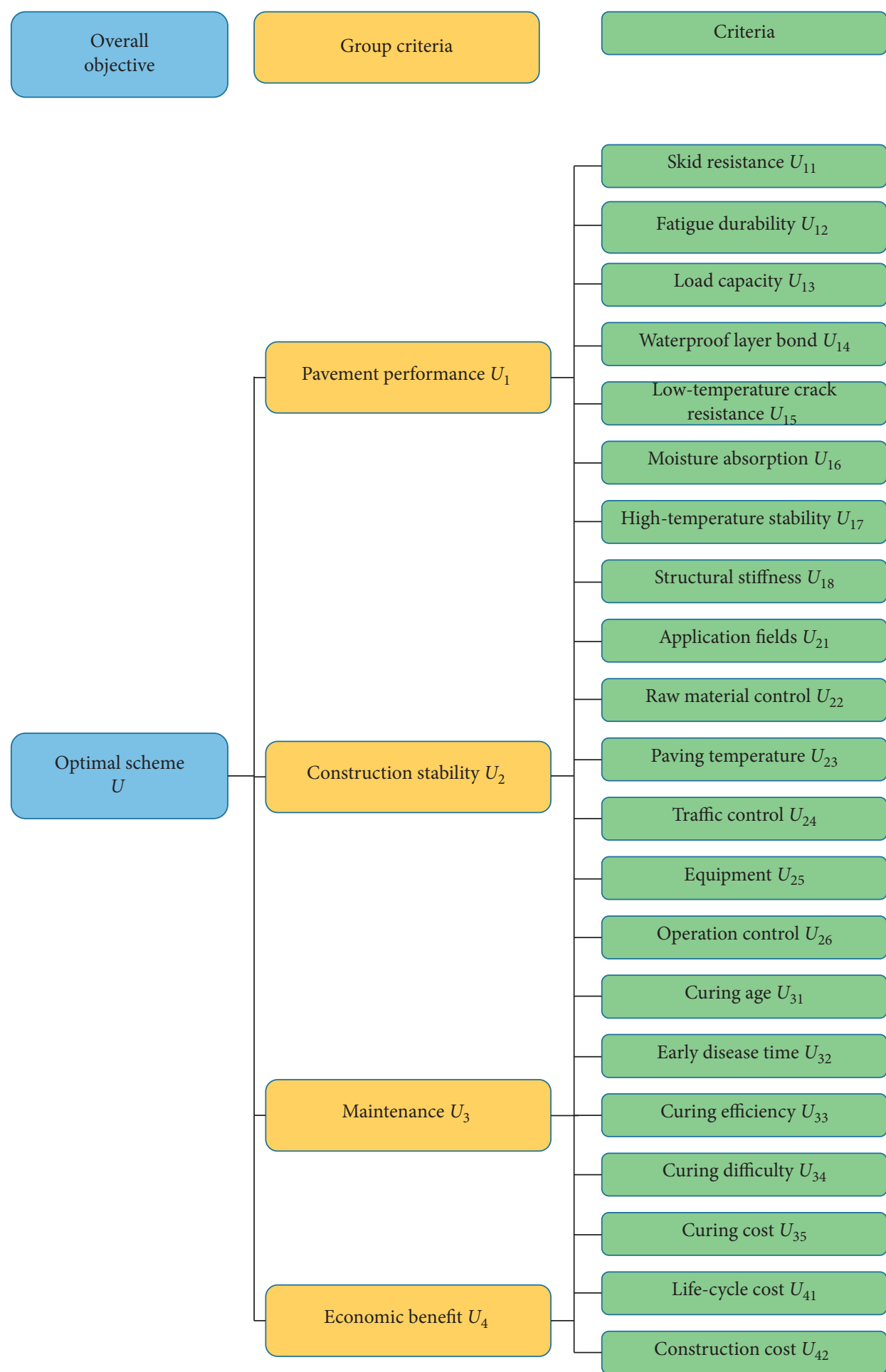

FIGURE 1: The hierarchical structure for pavement by the AHP method. 
TABLE 1: The value of $a_{i j}$ by 1-9 scale.

\begin{tabular}{lc}
\hline Value & Definition \\
\hline 1 & Equal importance \\
2 & Weak \\
3 & Moderate importance \\
4 & Moderate plus \\
5 & Strong importance \\
6 & Strong plus \\
7 & Very strong or demonstrate importance \\
8 & Very, very strong \\
9 & Extreme importance \\
\hline
\end{tabular}

TABLE 2: Random consistency index of 1-12 dominations by Saaty.

\begin{tabular}{ccccccccccccc}
\hline$n$ & 1 & 2 & 3 & 4 & 5 & 6 & 7 & 8 & 9 & 10 & 11 & 12 \\
\hline $\mathrm{RI}$ & 0 & 0 & 0.52 & 0.89 & 1.12 & 1.26 & 1.36 & 1.41 & 1.46 & 1.49 & 1.52 & 1.54 \\
\hline
\end{tabular}

2.4. The Fuzzy Assessment. Since the available judgment matrix and the weight vector for criteria were determined, a fuzzy evaluation method was used to evaluate the overall purpose of scheme. At first, each element was judged with a fuzzy judgment set $A=$ (excellent good moderate weak) with four levers. Then, considering the current standard and the reviewers' comments, a fuzzy evaluation matrix $R$ was built as equation (6). At last, the fuzzy comprehensive evaluation matrix $V$ for judgment matrix $U$ was calculated by equation (7), and the scheme with the highest $V$ value was supposed to be the optimal one:

$$
\begin{aligned}
R=\left[\begin{array}{c}
R_{1} \\
R_{2} \\
\ldots \\
R_{n}
\end{array}\right] & =\left[\begin{array}{llll}
r_{11} & r_{12} & \ldots & r_{1 m} \\
r_{21} & r_{22} & \ldots & r_{2 m} \\
\ldots & \ldots & \ldots & \ldots \\
r_{n 1} & r_{n 2} & \ldots & r_{n m}
\end{array}\right], \\
V & =R \cdot W,
\end{aligned}
$$

where $n$ is the number of criteria, $m$ is the dimension of fuzzy judgment set $A, r_{n m}$ is the ratio that element $n$ in level $m$ and $r_{n m} \in(0,1)$, and $W$ is the weight vector for judgment matrix $U$.

\section{Results and Discussion}

3.1. Judgment Matrix. The overall judgment matrix $U$ was built as $U=\left[U_{1} U_{2} U_{3} U_{4}\right]$ according to Figure $1 . U_{1}$ to $U_{4}$ are junior judgment matrixes, which corresponded to pavement performance, construction stability, maintenance, and economic benefit, respectively.

According to AHP structure in Figure 1, matrix $U_{1}$ contained 8 factors, which were skid resistance, fatigue durability, load capacity, waterproof layer bond, low-temperature crack resistance, moisture absorption, high-temperature stability, and structural stiffness, denoted as $U_{11}$ to $U_{18}$. Matrix $U_{2}$ had 6 factors, including working condition, raw material control, paving temperature, traffic control, equipment, and operation control, signed as $U_{21}$ to $U_{26}$. Matrix $U_{3}$ was composed by 5 factors, that is, curing age, early disease time, curing efficiency, curing difficulty, and curing cost, which is defined as $U_{31}$ to $U_{35}$. At last, matrix $U_{4}$ included 2 factors, life-cycle cost for $U_{41}$ and construction cost for $U_{42}$. The relative importance for each element was briefly analysed as follows.

The service condition of the Fourth Bridge is mainly high temperature, rainy weather, and heavy traffic, and the annual average temperature meets the requirement index for lowtemperature crack resistance so that the fatigue durability, waterproof layer bond, and high-temperature stability of steel deck pavement are important aspects which need more consideration, and the skid resistance and moisture absorption can be optimized by external design as well. In terms of construction stability, the quality of pavement was directly affected by material control, while the operation control, the paving temperature, and the traffic control can be adjusted according to the practical condition during construction. In maintenance issues, the early disease time directly determined the service life of pavement, and curing age and curing efficiency depend on the disease time and disease type. Also, the construction cost is much higher than life-cycle cost to ensure the long service life of the steel deck pavement.

Hence, we comprehensively consider the local condition, the relevant specification, and the reviewers' comments, and the relative importance for elements in senior judgment matrix $U$ and junior matrixes $U_{1}$ to $U_{4}$, and the calculated weight are listed in Tables 3-7.

The weight vector for junior judgment matrix $U_{1}$ to $U_{4}$ and senior matrix $U$ was as follows:

(i) $W_{1}=\left[\begin{array}{llllll}0.0596 & 0.2848 & 0.1183 & 0.1636 & 0.0806 & 0.0766\end{array}\right.$ $0.14260 .0739]$

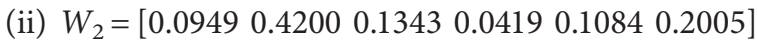

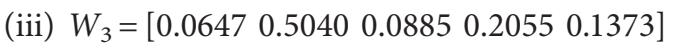

(iv) $W_{4}=\left[\begin{array}{ll}0.25 & 0.75\end{array}\right]$

(v) $W=\left[\begin{array}{llll}0.5441 & 0.1868 & 0.1229 & 0.1462\end{array}\right]$

3.2. The Consistency Test. After the calculation with equations (6)-(8), the value of $\lambda_{\max }, \mathrm{CI}, \mathrm{RI}$, and CR for each judgment matrix are present in Table 8 .

From Table 8, it is seen that all CR results for each judgment matrix were less than $10 \%$, which indicate that all the judgment matrixes here were available.

3.3. The Fuzzy Evaluation. Four schemes, including gussasphalt plus high-elastic asphalt concrete $(G A+A C)$, double-layer epoxy asphalt (D-EA), epoxy bonding chip layer/resin asphalt/store mastic asphalt multilayer pavement (ERS), and double-layer store mastic asphalt (D-SMA), were proposed for the Fourth Nanjing Yangtze River Bridge steel 
TABLE 3: Judgment matrix of optimum scheme evaluation of steel bridge deck pavement.

\begin{tabular}{lcccc}
\hline$U$ & $U_{1}$ & $U_{2}$ & $U_{3}$ & \\
\hline$U_{1}$ & 1 & 3 & 4 & 4 \\
$U_{2}$ & $1 / 3$ & 1 & 1 & 2 \\
$U_{3}$ & $1 / 4$ & 1 & 1 & $1 / 2$ \\
$U_{4}$ & $1 / 4$ & $1 / 2$ & 2 & 1 \\
Weight & 0.5441 & 0.1868 & 0.1229 & 0.1462 \\
\hline
\end{tabular}

TABLE 4: Judgment matrix of performance for steel deck pavement.

\begin{tabular}{lccccccc}
\hline$U_{1}$ & $U_{11}$ & $U_{12}$ & $U_{13}$ & $U_{14}$ & $U_{15}$ & $U_{16}$ & $U_{17}$ \\
\hline$U_{11}$ & 1 & $1 / 5$ & $1 / 3$ & 1 & 1 & $1 / 3$ & $1 / 3$ \\
$U_{12}$ & 5 & 1 & 5 & 1 & 3 & 3 & 3 \\
$U_{13}$ & 3 & $1 / 5$ & 1 & 1 & 2 & 3 & 1 \\
$U_{14}$ & 1 & 1 & 1 & 1 & 2 & 3 & $1 / 2$ \\
$U_{15}$ & 1 & $1 / 3$ & $1 / 2$ & $1 / 2$ & 1 & 1 & 2 \\
$U_{16}$ & 3 & $1 / 3$ & $1 / 3$ & $1 / 3$ & 1 & 1 & $1 / 2$ \\
$U_{17}$ & 3 & $1 / 3$ & 2 & $1 / 2$ & 2 & 2 & $1 / 2$ \\
$U_{18}$ & 1 & $1 / 3$ & 1 & $1 / 2$ & $1 / 2$ & 1 & 1 \\
Weight & 0.0596 & 0.2848 & 0.1183 & 0.1636 & 0.0806 & 0.0766 & $1 / 2$ \\
\hline
\end{tabular}

TABLE 5: Judgment matrix of construction controllability.

\begin{tabular}{|c|c|c|c|c|c|c|}
\hline$U_{2}$ & $U_{21}$ & $U_{22}$ & $U_{23}$ & $U_{24}$ & $U_{25}$ & $U_{26}$ \\
\hline$U_{21}$ & 1 & $1 / 5$ & $1 / 2$ & 3 & 1 & $1 / 2$ \\
\hline$U_{22}$ & 5 & 1 & 5 & 5 & 3 & 3 \\
\hline$U_{23}$ & 2 & $1 / 5$ & 1 & 3 & 2 & $1 / 2$ \\
\hline$U_{24}$ & $1 / 3$ & $1 / 5$ & $1 / 3$ & 1 & $1 / 4$ & $1 / 5$ \\
\hline$U_{25}$ & 1 & $1 / 3$ & $1 / 2$ & 4 & 1 & $1 / 2$ \\
\hline$U_{26}$ & 2 & $1 / 3$ & 2 & 5 & 2 & 1 \\
\hline Weight & 0.0949 & 0.4200 & 0.1343 & 0.0419 & 0.1084 & 0.2005 \\
\hline
\end{tabular}

TABLE 6: Judgment matrix of maintenance for steel deck pavement.

\begin{tabular}{|c|c|c|c|c|c|}
\hline$U_{3}$ & $U_{31}$ & $U_{32}$ & $U_{33}$ & $U_{34}$ & $U_{35}$ \\
\hline$\overline{U_{31}}$ & 1 & $1 / 4$ & $1 / 2$ & $1 / 3$ & $1 / 3$ \\
\hline$U_{32}$ & 4 & 1 & 5 & 4 & 5 \\
\hline$U_{33}$ & 2 & $1 / 5$ & 1 & $1 / 3$ & $1 / 2$ \\
\hline$U_{34}$ & 3 & $1 / 4$ & 3 & 1 & 2 \\
\hline$U_{35}$ & 3 & $1 / 5$ & 2 & $1 / 2$ & 1 \\
\hline Weight & 0.0647 & 0.5040 & 0.0885 & 0.2055 & 0.1373 \\
\hline
\end{tabular}

TABLE 7: Judgment matrix of economic benefit of steel deck pavement.

\begin{tabular}{lcc}
\hline$U_{4}$ & $U_{41}$ & \\
\hline$U_{41}$ & 1 & $U_{42}$ \\
$U_{42}$ & 3 & $1 / 3$ \\
Weight & 0.25 & 1 \\
\hline
\end{tabular}

TABLE 8: The consistency test results of each judgment matrix.

\begin{tabular}{lccccc}
\hline Index & $U$ & $U_{1}$ & $U_{2}$ & $U_{3}$ & $U_{4}$ \\
\hline$\lambda_{\max }$ & 4.1866 & 8.6762 & 6.2809 & 5.2608 & 2.0000 \\
CI & 0.0622 & 0.0966 & 0.0562 & 0.0652 & 0 \\
RI & 0.89 & 1.41 & 1.26 & 1.12 & 0 \\
CR & 0.0699 & 0.0685 & 0.0446 & 0.0582 & 0 \\
\hline
\end{tabular}


TABLE 9: The final score for different schemes.

\begin{tabular}{lcccc}
\hline Scheme & GA + AC & D-EA & ERS & D-SMA \\
\hline Score & 76.31 & 73.85 & 68.23 & 66.14 \\
\hline
\end{tabular}

deck pavement. For each scheme, four junior judgment matrixes $\left(U_{1}\right.$ to $\left.U_{4}\right)$ were evaluated by 6 judgers using fuzzy judgment set $A$, and then a fuzzy evaluation was output. The fuzzy evaluation matrixes $R_{1}$ to $R_{4}$ for each scheme are shown as follows:

$$
\begin{aligned}
& R_{1-\mathrm{GA}+\mathrm{AC}}=\left[\begin{array}{cccc}
0 & 0.85 & 0.15 & 0 \\
1 & 0 & 0 & 0 \\
0.9 & 0.1 & 0 & 0 \\
0.9 & 0.1 & 0 & 0 \\
0.9 & 0.1 & 0 & 0 \\
1 & 0 & 0 & 0 \\
0.9 & 0.1 & 0 & 0 \\
0.9 & 0.1 & 0 & 0
\end{array}\right], \\
& R_{1-D-E A}=\left[\begin{array}{cccc}
0.9 & 0.1 & 0 & 0 \\
0.8 & 0.1 & 0.1 & 0 \\
0.8 & 0.1 & 0.1 & 0 \\
0.75 & 0.15 & 0.1 & 0 \\
0.75 & 0.25 & 0 & 0 \\
0.9 & 0.1 & 0 & 0 \\
0.75 & 0.15 & 0.1 & 0 \\
0.85 & 0.1 & 0.05 & 0
\end{array}\right] \text {, } \\
& R_{2-\mathrm{GA}+\mathrm{AC}}=\left[\begin{array}{cccc}
0.85 & 0.15 & 0 & 0 \\
0.9 & 0.1 & 0 & 0 \\
1 & 0 & 0 & 0 \\
0.8 & 0.2 & 0 & 0 \\
0.85 & 0.15 & 0 & 0 \\
0.85 & 0.15 & 0 & 0
\end{array}\right], \\
& R_{2-\mathrm{D}-\mathrm{EA}}=\left[\begin{array}{cccc}
0.8 & 0.15 & 0.05 & 0 \\
0.9 & 0.1 & 0 & 0 \\
0.85 & 0.15 & 0 & 0 \\
1 & 0 & 0 & 0 \\
0.9 & 0.1 & 0 & 0 \\
0.95 & 0.05 & 0 & 0
\end{array}\right] \text {, } \\
& R_{2-\text { ERS }}=\left[\begin{array}{cccc}
0.75 & 0.15 & 0.1 & 0 \\
0.8 & 0.15 & 0.05 & 0 \\
0.85 & 0.15 & 0 & 0 \\
0.8 & 0.1 & 0.1 & 0 \\
0.85 & 0.15 & 0 & 0 \\
0.8 & 0.1 & 0.1 & 0
\end{array}\right],
\end{aligned}
$$

$$
R_{2 \text {-D-SMA }}=\left[\begin{array}{cccc}
0.9 & 0.1 & 0 & 0 \\
0.8 & 0.15 & 0.05 & 0 \\
0.85 & 0.15 & 0 & 0 \\
0.7 & 0.15 & 0.15 & 0 \\
0.8 & 0.15 & 0.05 & 0 \\
0.7 & 0.15 & 0.1 & 0.05
\end{array}\right],
$$$$
R_{3-\mathrm{GA}+\mathrm{AC}}=\left[\begin{array}{cccc}
0.9 & 0.1 & 0 & 0 \\
0.8 & 0.1 & 0.1 & 0 \\
0.8 & 0.2 & 0 & 0 \\
0.85 & 0.1 & 0.05 & 0 \\
0.85 & 0.1 & 0.05 & 0
\end{array}\right],
$$$$
R_{3-\mathrm{D}-\mathrm{EA}}=\left[\begin{array}{cccc}
0.9 & 0.1 & 0 & 0 \\
0.7 & 0.15 & 0.15 & 0 \\
0.85 & 0.15 & 0 & 0 \\
0.85 & 0.1 & 0.05 & 0 \\
0.9 & 0.1 & 0 & 0
\end{array}\right],
$$$$
R_{3-\mathrm{ERS}}=\left[\begin{array}{cccc}
0.8 & 0.1 & 0.1 & 0 \\
0.8 & 0.1 & 0.1 & 0 \\
0.8 & 0.1 & 0.1 & 0 \\
0.9 & 0.1 & 0 & 0 \\
0.9 & 0.1 & 0 & 0
\end{array}\right],
$$$$
R_{3-\mathrm{D}-\mathrm{SMA}}=\left[\begin{array}{cccc}
0.7 & 0.2 & 0.1 & 0 \\
0.7 & 0.2 & 0.1 & 0 \\
0.75 & 0.15 & 0.1 & 0 \\
0.8 & 0.1 & 0.1 & 0 \\
0.8 & 0.15 & 0.05 & 0
\end{array}\right],
$$$$
R_{4-\mathrm{GA}+\mathrm{AC}}=\left[\begin{array}{cccc}
0.8 & 0.1 & 0.05 & 0.05 \\
0.85 & 0.1 & 0.05 & 0
\end{array}\right],
$$$$
R_{4-\mathrm{D}-\mathrm{EA}}=\left[\begin{array}{cccc}
0.8 & 0.15 & 0.05 & 0 \\
0.9 & 0.1 & 0 & 0
\end{array}\right],
$$$$
R_{4-\mathrm{ERS}}=\left[\begin{array}{cccc}
0.8 & 0.1 & 0.1 & 0 \\
0.75 & 0.2 & 0.05 & 0
\end{array}\right],
$$$$
R_{4-\mathrm{D}-\mathrm{SMA}}=\left[\begin{array}{cccc}
0.75 & 0.15 & 0.1 & 0 \\
0.65 & 0.2 & 0.15 & 0
\end{array}\right] .
$$

Taking the GA+AC scheme as example, the fuzzy comprehensive evaluation matrix $V_{\mathrm{i}}$ for each junior judgment matrix was calculated by equation (7), and the results were 


$$
\begin{aligned}
V_{1} & =W_{1} \cdot R_{1}=\left[\begin{array}{llll}
0.8825 & 0.1086 & 0.0089 & 0
\end{array}\right], \\
V_{2} & =W_{2} \cdot R_{2}=\left[\begin{array}{llll}
0.8891 & 0.1110 & 0 & 0
\end{array}\right], \\
V_{3} & =W_{3} \cdot R_{3}=\left[\begin{array}{llll}
0.8236 & 0.1089 & 0.0675 & 0
\end{array}\right], \\
V_{4} & =W_{4} \cdot R_{4}=\left[\begin{array}{llll}
0.8375 & 0.1000 & 0.0500 & 0.0125
\end{array}\right] .
\end{aligned}
$$

Then, the fuzzy evaluation matrix $R$ for senior judgment matrix $U$ was exported as

$$
R_{\mathrm{GA}+\mathrm{AC}}=\left[\begin{array}{c}
V_{1} \\
V_{2} \\
V_{3} \\
V_{4}
\end{array}\right]=\left[\begin{array}{cccc}
0.8825 & 0.1086 & 0.0089 & 0 \\
0.8891 & 0.1110 & 0 & 0 \\
0.8236 & 0.1089 & 0.0675 & 0 \\
0.8375 & 0.1000 & 0.0500 & 0.0125
\end{array}\right] .
$$

The fuzzy evaluation matrix $V$ for matrix $U$ was also calculated by equation (7):

$$
\begin{aligned}
V_{\mathrm{GA}+\mathrm{AC}} & =\left[\begin{array}{llll}
0.8666 & 0.1074 & 0.0239 & 0.0022
\end{array}\right], \\
V_{\mathrm{D}-\mathrm{EA}} & =\left[\begin{array}{llll}
0.8263 & 0.1180 & 0.0557 & 0
\end{array}\right], \\
V_{\mathrm{ERS}} & =\left[\begin{array}{llll}
0.8030 & 0.1681 & 0.0289 & 0
\end{array}\right], \\
V_{\text {D-SMA }} & =\left[\begin{array}{llll}
0.7943 & 0.1340 & 0.0717 & 0
\end{array}\right] .
\end{aligned}
$$

The evaluation score was the normalization for $V$. After calculation, the evaluation score for four schemes is shown in Table 9.

The results indicated that the scheme GA + AC with the highest score was the optimal scheme.

\section{Conclusion}

In this paper, in order to fast and comprehensively assess the steel deck pavement scheme for the Fourth Nanjing Yangtze River Bridge, a fuzzy evaluation method was used to well evaluate the impact criteria. Four alternative schemes were analysed by this method to find the optimal one. The results of this work were summarized as follows:

(1) To comprehensively estimate the optimal scheme of pavement on the Fourth Bridge, all aspects including 21 criteria were selected to assess the overall properties. A three-level logical hierarchical structure containing four judge roles was built according to the AHP method.

(2) The weight of each judgment matrix was determined by the Delphi method, and then the evaluation for the judgment matrix was conducted using the fuzzy evaluation method.

(3) This fuzzy comprehensive evaluation method was helpful for the scheme decision for large-span bridge steel deck pavement.

\section{Data Availability}

The Table 2 data used to support the findings of this study have been deposited in research article by Thomas L Saaty (DOI: 10.1016/0022-2496(77)90033-5). The Tables 3-8 data used to support the findings of this study are original and included within the article. The matrix $R_{1}-R_{4}$ data used to support the findings of this study are original and included within the article.

\section{Conflicts of Interest}

The authors declare that there are no conflicts of interest regarding the publication of this paper.

\section{Acknowledgments}

This research was funded by the National Key Research and Development Program (Grant No. 2020YFA0714302), Ph.D initial funding of Anhui Jianzhu University (Grant No. 2019QDZ15), and the Natural Science Foundation of Anhui Province (Grant No. 2008085QE246).

\section{References}

[1] J. Simon, L. G. Vigh, A. Horváth, and P. Pusztai, “Application and assessment of equivalent linear analysis method for conceptual seismic retrofit design of háros M0 highway bridge," Periodica Polytechnica Civil Engineering, vol. 59, no. 2, pp. 109-122, 2015.

[2] Z. Gao, L. Yi, and H. Z. Xiao, "Dashengguan bridge-the largest span steel arch bridge for high-speed railway," Structural Engineering International, vol. 20, no. 3, pp. 299-302, 2010.

[3] Q. Wang, Y. Tan, L. Lian, and H. Wang, "Design and construction of a highway double-deck suspension bridge," Transportation Research Record: Journal of the Transportation Research Board, vol. 2573, no. 1, pp. 125-133, 2016.

[4] P. Li, G. Li, L. Qiao et al., "Modeling the tidal dynamic changes induced by the bridge in Jiaozhou bay, Qingdao, China," Continental Shelf Research, vol. 84, pp. 43-53, 2014.

[5] M. Feng, "Modern bridges in China," Structure and Infrastructure Engineering, vol. 10, no. 4, pp. 429-442, 2014.

[6] Y. Ge and Y. Yuan, "State-of-the-art technology in the construction of sea-crossing fixed links with a bridge, island, and tunnel combination," Engineering, vol. 5, no. 1, pp. 15-21, 2019.

[7] T. W. Kim, J. Baek, H. J. Lee, and S. Y. Lee, "Effect of pavement design parameters on the behaviour of orthotropic steel bridge deck pavements under traffic loading," International Journal of Pavement Engineering, vol. 15, no. 5, pp. 471-482, 2014.

[8] H. Yin, H. Jin, C. Wang et al., "Thermal, damping, and mechanical properties of thermosetting epoxy-modified asphalts," Journal of Thermal Analysis and Calorimetry, vol. 115, no. 2, pp. 1073-1080, 2014.

[9] Y. Zhang, X. Pan, Y. Sun et al., "Flame retardancy, thermal, and mechanical properties of mixed flame retardant modified epoxy asphalt binders," Construction and Building Materials, vol. 68, pp. 62-67, 2014.

[10] Q. Lu and J. Bors, "Alternate uses of epoxy asphalt on bridge decks and roadways," Construction and Building Materials, vol. 78, pp. 18-25, 2015.

[11] Y. Yang, Z. Qian, and X. Song, "A pothole patching material for epoxy asphalt pavement on steel bridges: fatigue test and numerical analysis," Construction and Building Materials, vol. 94, pp. 299-305, 2015.

[12] L.-T. Geng, Q. Xu, R.-B. Ren, L.-Z. Wang, X.-L. Yang, and X.-Y. Wang, "Performance research of high-viscosity asphalt 
mixture as deck-paving materials for steel bridges," Road Materials and Pavement Design, vol. 18, no. 1, pp. 208-220, 2017.

[13] Y. Liu, Z. H. Xi, J. Cai, and H. F. Xie, "Laboratory investigation of the properties of epoxy asphalt rubber (EAR)," Materials and Structures, vol. 50, no. 5, 2017.

[14] Y. Liu, J. Zhang, Y. Jiang et al., "Investigation of secondary phase separation and mechanical properties of epoxy SBSmodified asphalts," Construction and Building Materials, vol. 165, pp. 163-172, 2018.

[15] J. Si, Z. Jia, J. Wang et al., "Comparative analysis of cold-mixed epoxy and epoxy SBS-modified asphalts: curing rheology, thermal, and mechanical properties," Construction and Building Materials, vol. 176, pp. 165-171, 2018.

[16] S. Luo, Z. Qian, X. Yang, and H. Wang, "Design of gussasphalt mixtures based on performance of gussasphalt binders, mastics and mixtures," Construction and Building Materials, vol. 156, pp. 131-141, 2017.

[17] H. Y. Ye, X. C. Wang, N. R. Fang, and Z. Y. Su, "Lowtemperature performance and evaluation index of gussasphalt for steel bridge decks," Advances in Materials Science and Engineering, vol. 2019, Article ID 2951412, 11 pages, 2019.

[18] F. Xie, D. Zhang, A. Zhou, B. Ji, and L. Chen, "On the viscoelastic parameters of gussasphalt mixture based on modified burgers model: deviation and experimental verification," Advances in Materials Science and Engineering, vol. 2017, Article ID 4324765, 11 pages, 2017.

[19] H. Wang and G. Li, "Study of factors influencing gussasphalt mixture performance," Construction and Building Materials, vol. 101, pp. 193-200, 2015.

[20] T. W. Kim, J. Baek, H. J. Lee, and J. Y. Choi, "Fatigue performance evaluation of SBS modified mastic asphalt mixtures," Construction and Building Materials, vol. 48, pp. 908-916, 2013.

[21] Y. Cheng, J. Tao, Y. Jiao et al., "Influence of the properties of filler on high and medium temperature performances of asphalt mastic," Construction and Building Materials, vol. 118, pp. 268-275, 2016.

[22] G. G. Ai-Khateeb, M. F. Irfaeya, and T. S. Khedaywi, "A new simplified micromechanical model for asphalt mastic behavior," Construction and Building Materials, vol. 149, pp. 587-598, 2017.

[23] S. Luo and Z. Qian, "Preparation and performance evaluation of novel high durability epoxy asphalt concrete for bridge deck pavements," Asian Journal of Chemistry, vol. 26, no. 17, pp. 5595-5598, 2014.

[24] E. Bocci, A. Graziani, and F. Canestrari, "Mechanical 3D characterization of epoxy asphalt concrete for pavement layers of orthotropic steel decks," Construction and Building Materials, vol. 79, pp. 145-152, 2015.

[25] Z.-D. Qian, Y. Liu, C.-B. Liu, and D. Zheng, "Design and skid resistance evaluation of skeleton-dense epoxy asphalt mixture for steel bridge deck pavement," Construction and Building Materials, vol. 114, pp. 851-863, 2016.

[26] Y. Xue, H. Hou, S. Zhu, and J. Zha, "Utilization of municipal solid waste incineration ash in stone mastic asphalt mixture: pavement performance and environmental impact," Construction and Building Materials, vol. 23, no. 2, pp. 989-996, 2009.

[27] C. E. Sengul, S. Oruc, E. Iskender, and A. Aksoy, "Evaluation of SBS modified stone mastic asphalt pavement performance," Construction and Building Materials, vol. 41, pp. 777-783, 2013.

[28] Z. Leng, I. L. Al-Qadi, and R. Cao, "Life-cycle economic and environmental assessment of warm stone mastic asphalt,"
Transportmetrica A: Transport Science, vol. 14, no. 7, pp. 562-575, 2018.

[29] S. Fernandes, H. M. R. D. Silva, and J. R. M. Oliveira, "Mechanical, surface and environmental evaluation of stone mastic asphalt mixtures with advanced asphalt binders using waste materials," Road Materials and Pavement Design, vol. 20, no. 2, pp. 316-333, 2019.

[30] S. Luo, Z. D. Qian, X. Yang, and Q. Lu, "Laboratory evaluation of double-layered pavement structures for long-span steel bridge decks," Journal of Materials in Civil Engineering, vol. 30, no. 6, 2018.

[31] Y. Q. Pan, Z. X. Zhang, and R. J. Cao, "Research on ERS steel deck pavement techniques," Journal of Testing and Evaluation, vol. 40, no. 7, pp. 1260-1265, 2012.

[32] X. Liu, C. Zhou, D. Feng, X. Fan, and S. Xie, "Experimental study on interlayer shear properties of ERS pavement system for long-span steel bridges," Construction and Building $\mathrm{Ma}$ terials, vol. 143, pp. 198-209, 2017.

[33] Á. García, "Self-healing of open cracks in asphalt mastic," Fuel, vol. 93, pp. 264-272, 2012.

[34] L. Li, Y. Gao, and Y. Zhang, "Crack length based healing characterisation of bitumen at different levels of cracking damage," Journal of Cleaner Production, vol. 258, Article ID 120709, 2020.

[35] R. C. Battista, M. S. Pfeil, and E. M. L. Carvalho, "Fatigue life estimates for a slender orthotropic steel deck," Journal of Constructional Steel Research, vol. 64, no. 1, pp. 134-143, 2008.

[36] F. N. Leitão, J. G. S. Da Silva, P. C. G. D. Vellasco, S. A. L. De Andrade, and L. R. O. De Lima, "Composite (steelconcrete) highway bridge fatigue assessment," Journal of Constructional Steel Research, vol. 67, no. 1, pp. 14-24, 2011.

[37] Z. Qian, L. Chen, C. Jiang, and S. Luo, "Performance evaluation of a lightweight epoxy asphalt mixture for bascule bridge pavements," Construction and Building Materials, vol. 25, no. 7, pp. 3117-3122, 2011.

[38] C. Y. Wu and Z. X. Zhang, "Mechanical analysis for the deck pavement of long-span steel bridge," Advanced Materials Research, vol. 378-379, pp. 302-305, 2011.

[39] I. F. Alcover, J. E. Andersen, and M. K. Chryssanthopoulos, "Performance assessment and prediction of welded joints in orthotropic decks considering hourly monitoring data," Structural Engineering International, vol. 23, no. 4, pp. 436-442, 2013.

[40] C. Cui, Q. H. Zhang, H. Hao, J. Li, and Y. Z. Bu, "Influence of asphalt pavement conditions on fatigue damage of orthotropic steel decks: parametric analysis," Journal of Bridge Engineering, vol. 23, no. 12, Article ID 04018093, 2018.

[41] P. Pokorski, P. Radziszewski, and M. Sarnowski, "Fatigue life of asphalt pavements on bridge decks," Procedia Engineering, vol. 153, pp. 556-562, 2016.

[42] S. Luo, Z. Qian, X. Yang, and Q. Lu, "Fatigue behavior of epoxy asphalt concrete and its moisture susceptibility from flexural stiffness and phase angle," Construction and Building Materials, vol. 145, pp. 506-517, 2017.

[43] J. Li, C. Deng, Y. Li, Y. J. Li, and J. X. Song, "Comprehensive benefit evaluation system for low-impact development of urban stormwater management measures," Water Resources Management, vol. 31, pp. 4745-4758, 2017.

[44] O. U. Bayrak and H. F. Bayata, "Multi-criteria decision-based safety evaluation using microsimulation," Proceedings of the Institution of Civil Engineers-Transport, vol. 173, no. 5, pp. 345-357, 2020.

[45] A. Ishizaka and A. Labib, "Review of the main developments in the analytic hierarchy process," Expert Systems with Applications, vol. 38, no. 11, pp. 14336-14345, 2011. 
[46] Z. Ma, C. Shao, S. Ma, and Z. Ye, "Constructing road safety performance indicators using fuzzy Delphi method and grey Delphi method," Expert Systems with Applications, vol. 38, no. 3, pp. 1509-1514, 2011.

[47] M. R. Hallowell and J. A. Gambatese, "Qualitative research: application of the Delphi method to CEM research," Journal of Construction Engineering and Management, vol. 136, no. 1, pp. 99-107, 2010.

[48] T. L. Saaty, "A scaling method for priorities in hierarchical structures," Journal of Mathematical Psychology, vol. 15, no. 3, pp. 234-281, 1977. 